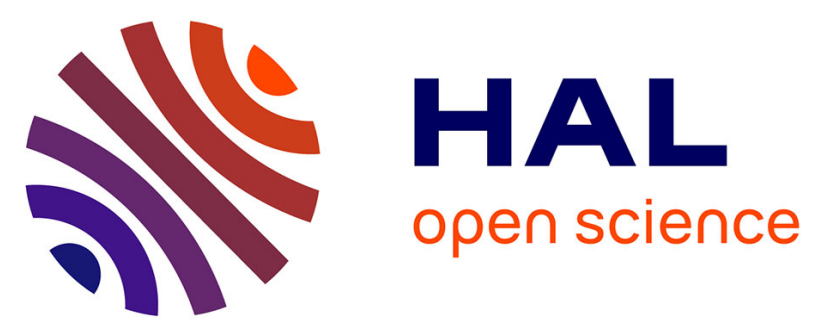

\title{
Quantitative Structure - Activity Relationship Study on Saponins as Cytotoxicity Enhancers
}

Reneta Gevrenova, Alexander Weng, Laurence Voutguenne-Nazabadioko, Mayank Thakur, Irini Doytchinova

\section{To cite this version:}

Reneta Gevrenova, Alexander Weng, Laurence Voutguenne-Nazabadioko, Mayank Thakur, Irini Doytchinova. Quantitative Structure - Activity Relationship Study on Saponins as Cytotoxicity Enhancers. Letters in Drug Design \& Discovery, 2014, 12 (3), pp.166-171. 10.2174/1570180811666140915221432 . hal-01996585

\section{HAL Id: hal-01996585 \\ https://hal.univ-reims.fr/hal-01996585}

Submitted on 2 Nov 2021

HAL is a multi-disciplinary open access archive for the deposit and dissemination of scientific research documents, whether they are published or not. The documents may come from teaching and research institutions in France or abroad, or from public or private research centers.
L'archive ouverte pluridisciplinaire HAL, est destinée au dépôt et à la diffusion de documents scientifiques de niveau recherche, publiés ou non, émanant des établissements d'enseignement et de recherche français ou étrangers, des laboratoires publics ou privés.

\section{(ㅇ)(1) $\$$}

Distributed under a Creative Commons Attribution - NonCommerciall 4.0 International 


\title{
Quantitative Structure - Activity Relationship Study on Saponins as Cytotoxicity Enhancers
}

Reneta Gevrenova ${ }^{1}$, Alexander Weng ${ }^{2}$, Laurence Voutguenne-Nazabadioko ${ }^{3}$, Mayank Thakur ${ }^{4}$, and Irini Doytchinova ${ }^{5 *}$

${ }^{1}$ Department of Pharmacognosy, Faculty of Pharmacy, Medical University of Sofia, 2 Dunav st., 1000 Sofia, Bulgaria

${ }^{2}$ Molecular Immunology Unit, UCL Institute of Child Health, 30 Guilford Street, London, WCIN 1EH, UK

${ }^{3}$ Institut of Molecular Chimistry of Reims, UMR CNRS 7312, Bâtiment 18, BP 1039, 51687 Reims cedex 2, France

${ }^{4}$ Institut für Laboratoriumsmedizin, Klinische Chemie und Pathobiochemie, CharitéUniversitätsmedizin Berlin, Campus Virchow-Klinikum, Augustenburger Platz 1, D-13353 Berlin, GERMANY

${ }^{5}$ Department of Chemistry, Faculty of Pharmacy, Medical University of Sofia, 2 Dunav st., 1000 Sofia, Bulgaria

\begin{abstract}
:
Saponins enhance the cytotoxicity of the type I ribosome-inactivating protein (RIP-I) saporin. In the present study, the synergistic cytotoxicity of nine newly isolated gypsogenin-containing saponins from Gypsophila trichotoma in combination with RIP-I was evaluated in vitro and used to derive a quantitative structure - activity relationship (QSAR). The QSAR model distinguished two important structural features of the studied saponins necessary for their cytotoxicity enhancing activity: the branched trisaccharide moiety attached to C-3 should contain one xylose residue instead of an arabinose and the branched tetrasaccharide at C-28 should contain one acetyl group attached to the glucose residue.
\end{abstract}

Keywords: saponins, saporin, QSAR, PLS, cytotoxicity, cancer, targeted anticancer therapy 


\section{INTRODUCTION}

Saponins are a structurally diverse class of compounds occurring in many plant species which are chemically referred to as triterpenoid and steroidal glycosides [1]. They consist of non-sugar aglycone and one or more sugar chains linked by glycosidic and (or) ester binding to the aglycone. Saponins have been reported to possess anti-tumor properties, to inhibit angiogenesis and to induce tumor apoptosis [2-4]. Other studies have reported that saponins play a role in the reduction of tumor invasiveness and multidrug resistance [5], which suggests that they could represent alternative agents in cancer treatment. In addition, it has been shown that saponins combined with some conventional chemotherapeutic agents exerted synergistic inhibitory effect on tumor growth in vitro and in vivo [3]. Moreover, saponin-adjuvanted particulate vaccines were reported to have great potential as cancer immunotherapeutics [6]. Among other interesting properties of saponins is their role in permeabilization and haemolysis [7].

Roots from Gypsophila species are an extremely rich source of triterpenoid saponins belonging to the group of GOTCAB saponins (glucuronide oleanane-type triterpenoid carboxylic acid 3,28-bidesmosides) [8-12]. Previous reports have shown that saponins from Gypsophila oldhamiana Miq. and Gypsophila pilulifera Boiss. \& Heldr. display cytotoxic activity against different human cancer cell lines [13-15].

It has also been reported that Saponinum album, G. paniculata and G. arrostii Guss. var. nebulosa (Caryophyllaceae) saponins enhance the cytotoxicity of the type I ribosomeinactivating protein (RIP-I) saporin from Saponaria officinalis L. [7, 11, 16-18]. The principle of the synergistic cytotoxicity was adopted for saporin-based targeted toxins which are used in tumour therapy $[12,19]$. Targeted toxins are proteins consisting of two components: a toxic protein and a cell-binding domain like the epidermal growth factor (EGF), which targets tumour associated antigens. Bachran et al. [20] have demonstrated that the targeted toxin in combination with Saponinum album enters cells via clathrin- and actin-dependent pathways [20]. Böttger et al. [21] have analyzed the structure - activity relationships of 56 saponins and their synergistic cytotoxicity with saporin and have defined the concept of ideal saponin. According to this concept, the ideal RIP-I synergistic saponin consists of an oleanane-type aglycone (gypsogenin or quillaic acid), a branched trisaccharide at C-3 including $\beta$-Dglucuronic acid, $\beta$-D-galactopyranose and $\beta$-D-xylopyranose and a branched tetrasaccharide at $\mathrm{C}-28$ including desoxy-sugars such as $\beta$-D-fucose and/or $\alpha$-L-rhamnose and acetyl residues.

Recently, fifteen new GOTCAB saponins were isolated from the roots of Gypsophila trichotoma Wend. var. trichotoma $[10,22]$. The saponins have a commonly found gypsogenin 
as an aglycone substituted at C-3 with a trisaccharide and at C-28 with an oligosaccharide bound to arginin, methoxycinnamoyl or acetyl and (or) sulfate groups. In addition, the aminoacyl saponins showed a synergistic effect enhancing the cytotoxicity of the targeted toxin saporin in HER14 cells [22]. In the present study, we evaluate the synergistic cytotoxicity of the newly isolated saponins from G. trichotoma in combination with RIP-1 saporin and investigate quantitatively their structure - activity relationships.

\section{MATERIALS AND METHODS}

\section{Dataset of Saponins}

The roots of Gypsophila trichotoma Wender var. trichotoma were procured from the Black Sea region (Balgarevo, Bulgaria). Triterpenoid saponins were isolated from Gypsophila trichotoma Wender var. trichotoma by solvent extraction (methanol, 25\%) followed by low pressure liquid chromatography $\left(\mathrm{RP}-\mathrm{C}_{8}\right)$ and semi-preparative HPLC $\left(\mathrm{RP}-\mathrm{C}_{18}\right)$ as described elsewhere $[10,22]$. Saponins were characterized on the basis of extensive NMR analysis $\left({ }^{1} \mathrm{H}\right.$, ${ }^{13} \mathrm{C}$ NMR, COSY, TOCSY, ROESY, HSQC, HMBC, and HSQC- TOCSY), completed by analysis of HR-ESI-MS and ESI-MS ${ }^{\mathrm{n}}$, as well as polarimetry, thin-layer chromatography and high-performance liquid chromatography $[10,22]$. The structures of the studied saponins are given in Figure 1.

\section{Antitumor Assay}

The antitumor assay was described in details elsewhere [7, 23]. Briefly, the tested saponins $(5 \mu \mathrm{g} / \mathrm{mL})$ were applied together with saporin-6 $(30 \mathrm{nM})$ on mammary breast cancer cell line MDA-MB-231 (ATCC ${ }^{\circ}$ HTB-26 ${ }^{\mathrm{TM}}$ ) and the cell viability was continuously monitored by Real-Time Cell Analyzer (RTCA) (xCELLigence system, Roche Applied Science, Mannheim, Germany). The activities of the studied saponins were represented by a cell index $(C I)$ per $1 \mu \mathrm{M}$ after 128 hours of incubation.

\section{Quantitative Structure - Activity Relationship (QSAR) Protocol}

The chemical structure of the studied saponins was described by five indicator variables: $1 \mathrm{R}, 2 \mathrm{COCH}_{3}, 3 \mathrm{SO}_{3} \mathrm{H}, 4 \mathrm{COCH}_{3}$ and $\mathrm{Xyl}$. If a substituent presents at a given position, the indicator variable takes value 1 ; otherwise it takes 0 . For example, the descriptor $1 R$ takes 1 if there are $\mathrm{COCH}_{3}$, cis- $p$-methoxycinnamoyl (CisMCin) or trans- $p$ methoxycinnamoyl groups (TransMCin) at position $\mathrm{R}_{1}$. Similarly, descriptors $2 \mathrm{COCH}_{3}$, $3 \mathrm{SO}_{3} \mathrm{H}, 4 \mathrm{COCH}_{3}$ take 1 if there are $\mathrm{COCH}_{3}, \mathrm{SO}_{3} \mathrm{H}$, and $\mathrm{COCH}_{3}$ at positions $\mathrm{R}_{2}, \mathrm{R}_{3}$ or $\mathrm{R}_{4}$, 
respectively (Figure 1). The descriptor $X y l$ takes 1 when a $\beta$-D-xylopyranose ( $\beta$-D-Xylp) residue exists in the carbohydrate part attached to position C-3. The activities of the studied saponins are represented by a cell index $(C I)$ per $1 \mu \mathrm{M}$ after 128 hours of incubation. Low $C I$ values correspond to highly active compounds. The QSAR model was derived by multiple linear regression (MLR) applying partial least squares (PLS) as implemented in SIMCA 13.0 (Umetrics Ltd.).

\section{RESULTS}

The cytotoxicity enhancing activities of the studied saponins given as a cell index $(C I)$ per $1 \mu \mathrm{M}$ after 128 hours of incubation are shown in Table 1 . The highly active compounds have low $C I$ values and vice versa. The studied saponins also were screened at concentrations of 5,10 and $20 \mu \mathrm{g} / \mathrm{mL}$ for self-toxicity (data not shown). No toxic effects were observed up to $20 \mu \mathrm{g} / \mathrm{mL}$ for a period of $128 \mathrm{~h}$ after incubation for all saponins.

Two principal components $(P C)$ account for $66 \%$ of the variance in the set. The first $P C$ accounts for $41.3 \%$; the second $P C$ adds $25.0 \%$. The score and loadings plots are given in Figure 2. The saponins $\mathbf{3}, \mathbf{7}$ and $\mathbf{8}$ overlap in the score plot as they have the same values for all descriptors (Figure 2a). The most active compound (saponin 5) is positioned in the third quadrant (lower left), the least active one (saponin 1) is just opposite, in the first quadrant (upper right). The loadings plot (Figure 2b) points to descriptors contributing positively (right part) and negatively (left part) to $\mathrm{CI}$. Descriptors $\mathrm{IR}, 2 \mathrm{COCH}_{3}$ and $3 \mathrm{SO}_{3} \mathrm{H}$ increase $\mathrm{CI}$, i.e. decrease activity; descriptors $4 \mathrm{COCH}_{3}$ and $\mathrm{Xyl}$ decrease $\mathrm{CI}$, i.e. increase activity. The derived QSAR model is:

$$
\begin{gathered}
C I=0.472 * I R+0.033 * 2 \mathrm{COCH}_{3}+0.335 * 3 \mathrm{SO}_{3} \mathrm{H}-0.515 * 4 \mathrm{COCH}_{3}-0.379 * \mathrm{Xyl}+2.328 \\
n=9 \quad r^{2}=0.708
\end{gathered}
$$

This model clearly revealed several trends in the structure - activity relationships of studied saponins:

- the presence of acetyl, cis- $p$-methoxycinnamoyl or trans- $p$-methoxycinnamoyl groups at position $\mathrm{R}_{1}$ increases $C I$, i.e. decreases activity;

- the presence of acetyl group at position $\mathrm{R}_{2}$ increases $C I$, i.e. decreases activity;

- the presence of sulfonyl group at position $\mathrm{R}_{3}$ increases $C I$, i.e. decreases activity;

- the presence of acetyl group at position $\mathrm{R}_{4}$ decreases $C I$, i.e. increases activity; 
- the presence of $\beta$-D-Xylp in the carbohydrate part attached to C-3 decreases $C I$, i.e. increases activity.

Hence, the synergistic cytotoxicity of the newly isolated saponins from G. trichotoma is facilitated by an acetylation at position $\mathrm{R}_{4}$ and by the presence of $\beta$-D-Xylp residue instead of $\alpha$-L-arabinopyranose ( $\alpha$-L-Arap) in the trisaccharide attached to $\mathrm{C}-3$ of the aglycon. The summarized results from the QSAR study are given in Figure 3.

In order to discriminate between the substituents at position $\mathrm{R}_{1}$, descriptor $1 R$ was replaced by two descriptors $1 \mathrm{COCH}_{3}$ and $1 \mathrm{Cin}$ accounting for the presence of $\mathrm{COCH}_{3}$ and CisMCin/TransMCin, respectively. The derived QSAR model (data not shown) showed that both descriptors have positive coefficients, i.e. decrease activity.

\section{DISCUSSION}

Saporins are ribosome-inactivating proteins (RIPs) extracted from roots, leaves and seeds of Saponaria officinalis, commonly known as soapwort [24]. Among the several saporins isolated from $S$. officinalis, saporin-6 is the most abundant and stable. RIPs are a family of plant toxins, which specifically and irreversibly inhibit protein synthesis in eukaryotic cells by removing one or more adenine residues from ribosomal RNA [25]. RIPs are classified into two types, referred as type I and type II. Type I RIPs are single-chain proteins, while type II RIPs consist of an enzimatically active A-chain and a B-chain with cell-binding ability [25]. The lack of cell-binding domain in RIPs-I limits their membrane permeability and decreases their cytotoxicity. It was found that RIP I become highly toxic if they are linked to appropriate carriers, like saponins, able to permeate through the cell membane [25].-It was found that saponins enhance the toxicity of certain RIPs-I synergistically at submicellar concentration [16]. Saponins mediate the endosomal escape of RIPs-I after internalization [21].

Saponins are amphiphilic molecules with surfactant activity. It was assumed that their cell permeability is due to the interaction with the membrane cholesterol leading to a rearrangement of the phospholipid bilayer and pore formation [26]. When saporin is applied in combination with saponins, its cytotoxic activity in vitro increases up to 100,000 times [16]. Recently, Böttger et al. [21] have suggested the most important structural features for the development of synergistic cytotoxicity between saponins and RIP-I.

Our results confirm and further develop Böttger's concept. The investigated saponins contain the aglycone gypsogenin, a branched trisaccharide chain at $\mathrm{C}-3$ containing $\beta$-D- 
glucuronic acid, $\beta$-D-galactopyranose, and $\beta$-D-Xylp or $\alpha$-L-Arap and a branched tetrasaccharide chain at $\mathrm{C}$-28 consisting of $\beta$-D-fucopyranose ( $\beta$-D-Fucp), $\alpha$-Lrhamnopyranose, $\alpha$-L-Arap and $\beta$-D-glucopyranose ( $\beta$-D-Glcp), some of them partially acetylated or sulfonated (Figure 1). The QSAR study showed that the presence of a monoacetylated $\beta$-D-Glcp residue (substituent $\mathrm{R}_{4}$ ) at C-28 tetrasaccharide and of $\beta$-D-Xylp at C-3 trisaccharide instead of $\alpha$-L-Arap increases the cytotoxic activity of saporin. The presence of a substitutent in the $\beta$-D-Fucp (substituents $\mathrm{R}_{1}$ and $\mathrm{R}_{2}$ ) and a sulfonated $\beta$-D-Glcp (substituent $\mathrm{R}_{3}$ ) attached to $\mathrm{C}-28$ sugar chain decreases the synergistic cytotoxicity.

The least active compound in the set is saponin $1(C I=0.307)$. It is monoacetylated in $\beta$-D-Fucp and sulfonated in $\beta$-D-Glcp moiety at the sugar chain attached to C-28, and contains $\alpha$-L-Arap at C-3 sugar chain. The most active compound saponin $5(C I=0.016)$ has monoacetylated $\beta$-D-Fucp and $\beta$-D-Glcp at C-28 tetrasaccharide and a $\beta$-D-Xylp residue at C3 trisaccharide. Very similar to saponin 5 is saponin $\mathbf{4}$ having an $\alpha$-L-Arap residue at C-3 trisaccharide instead of $\beta$-D-Xylp. However, the activity of saponin 4 is almost 14 times lower than the activity of saponin $5(C I=0.219$ and $C I=0.016$, respectively). This emphasizes the presence of $\beta$-D-Xylp in the branched trisaccharide attached to C-3 as an important new structural feature of saponins for cytotoxicity enhancing activity. The only difference between $\beta$-D-Xylp and $\alpha$-L-Arap is the orientation of 4-OH group: in $\beta$-D-Xylp it is in equatorial position, in $\alpha$-L-Arap - in axial. As such tiny structural difference results in a significant difference in activity, one might suppose a precise steric interaction with the biological target. It was found that equatorial hydroxyls formed more hydrogen bonds than axial groups [27]. Because of the higher accessible surface of equatorial groups, there is a definite tendency for them to be involved in two hydrogen bonds, whereas axial are more likely to form only one. The other $\beta$-D-Xylp-containing saponin in the set is compound 9. However, it contains no acetyl group in the $\beta$-D-Glcp attached to C-28 and its activity is almost 16 times lower than the activity of saponin 5 ( $C I=0.251$ and $C I=0.016$, respectively). Thus, the acetylated $\beta$-DGlcp residue at C-28 sugar chain is another important structural feature for the synergistic cytotoxicity of saponins.

In summary, a QSAR model was derived in the present study using multiple linear regression by partial least squares. The model distinguished the most important structural features of gypsogenin-containing saponins acting as cytotoxicity enhancers of the RIP-I saporin. The branched trisaccharide moiety attached to C-3 should contain one $\beta-\mathrm{D}-\mathrm{Xylp}$ residue instead of an $\alpha$-L-Arap. The branched tetrasaccharide at C-28 should contain one acetyl group attached to the $\beta$-D-Glcp residue. The fact that the saponins themselves are non- 
toxic but in a combined application with a RIP-I show synergistic cytotoxicity makes them perspective drug candidates for targeted anticancer therapy.

\section{REFERENCES}

[1] Vincken, J.-P.; Heng, L.; de Groot, A.; Gruppen, H. Saponins, classification and occurrence in the plant kingdom. Phytochemistry, 2007, 68, 275-297.

[2] Bachran, C.; Bachran, S.; Sutherland, M.; Bachran, D.; Fuchs H. Saponins in tumor therapy. Mini Rev. Med. Chem., 2008, 8, 575-584.

[3] Fuchs, H.; Bachran, D.; Panjideh, H.; Schellmann, N.; Weng, A.; Melzig, M.F.; Sutherland, M.; Bachran, C. Saponins as tool for improved targeted tumor therapies. Curr. Drug Targets, 2009, 10, 140-151.

[4] Podolak, I.; Galanty, A.; Sobolewska, D. Saponins as cytotoxic agents: A review. Phytochem. Rev., 2010, 9, 425-474.

[5] Yanamandra, N.; Berhow, M.A.; Konduri, S.; Dinh, D.H.; Olivero, W.C.; Nicolson, G.L.; Rao, J.S. Triterpenoids from Glycine max decrease invasiveness and induce caspase-mediated cell death in human SNB19 glioma cells. Clin. Exp. Metastasis, 2003, 20, 375-383.

[6] Skene, C.D.; Sutton P. Saponin-adjuvanted particulate vaccines for clinical use. Methods (San Diego, Calif.), 2006, 40, 53-59.

[7] Gilabert-Oriol, R.; Mergel, K.; Thakur, M.; Mallinckrodt, B.; Melzig, M.F.; Fuchs,H.; Weng, A. Real-time analysis of membrane permeabilizing effects of oleanane saponins. Bioorg. Med. Chem., 2013, 21, 2387-2395.

[8] Tan, N.; Zhou, J.; Zhao, S. Advances in structural elucidation of glucuronide oleananetype triterpene carboxylic acid 3, 28-O-bidesmosides (1962-1997). Phytochemistry, 1999, 52, 153-192.

[9] Henry M. Saponins and phylogeny: Example of the "Gypsogenin group" saponins. Phytochem. Rev., 2005, 4, 89-94.

[10] Gevrenova, R.; Voutquenne-Nazabadioko, L.; Harakat, D.; Prost, E.; Henry M. Complete ${ }^{1} \mathrm{H}$ and ${ }^{13} \mathrm{C}$ NMR assignments of saponins from roots of Gypsophila trichotoma Wend. Magn. Res. Chem., 2006, 44, 686-691.

[11] Weng, A.; Jenett-Siems, K.; Schmieder, P.; Bachran, D.; Bachran, C.; Gorick, C.; Thakur, M. A convenient method for saponin isolation in tumour therapy. J. Chromatogr. B, 2010, 878, 713-718.

[12] Bottger, S.; Melzig M.F. Triterpenoid saponins of the Caryophyllaceae and Illecebraceae family. Phytochem. Lett., 2010, 4, 59-68. 
[13] Bai, H.; Zhong, Y.; Xie, Y.Y.; Wang, Y.-S.; Liu, L.; Zhou, L. A major triterpenoid saponin from Gypsophila oldhamiana. Chem. Biodivers., 2007, 4, 955-60.

[14] Arslan, I.; Celik, A.; Chol, J.H. A cytotoxic triterpenoid saponin from under-ground parts of Gypsophila pilulifera Boiss.\& Heldr. Fitoterapia, 2012, 83, 699-703.

[15] Zhang, W.; Luo, J.-G.; Zhang, C.; Kong, L.-Y. Different apoptotic effects of triterpenoid saponin-rich Gypsophila oldhamiana root extract on human hepatoma SMMC-7721 and normal human hepatic L02 cells. Biol. Pharm. Bull., 2013, 36, 1080-1087.

[16] Hebestreit, P.; Weng, A.; Bachran, C.; Fuchs, H.; Melzig, M.F. Enhancement of cytotoxicity of lectins by Saponinum album. Toxicon, 2006, 47, 330-335.

[17] Weng, A.; Melzig, M.F.; Bachran, C.; Fuchs, H. Enhancement of saporin toxicity against U937 cells by Gypsophila saponins. J. Immunotoxicol., 2008, 5, 287-292.

[18] Arslan, I.; Celik, A.; Melzig, M.F. Nebulosides A-B, novel triterpene saponins from under-ground parts of Gypsophila arrostii Guss. var. nebulosa. Bioorg. Med. Chem., 2013, $21,1279-1283$.

[19] Bachran, C.; Durkop, H.; Sutherland, M.; Bachran, D.; Muller, C.; Weng, A.; Melzig, M.F.; Fuchs, H. Inhibition of tumor growth by targeted toxins in mice is massively improved by Saponinum album in a synergistic way. J. Immunother., 2009, 32, 713-725.

[20] Bachran, D.; Schneider S.; Bachran, C.; Weng, A.; Melzig, M.F.; Fuchs, H.The endocytic uptake pathways of targeted toxins are influenced by synergistically acting Gypsophila saponins. Mol. Pharmaceutics, 2011, 8, 2262-2272.

[21] Bottger, S.; Westhof, E.; Siems, K.; Melzig M.F. Structure-activity relationships of saponins enhancing the cytotoxicity of ribosome-inactivating proteins type I (RIP-I). Toxicon, 2013, 73, 144-150.

[22] Voutquenne-Nazabadioko, L.; Gevrenova, R.; Borie, N.; Harakat, D.; Sayagh, Ch.; Weng, A.; Thakur, M.; Zaharieva, M.; Henry, M. Triterpenoid saponins from the roots of Gypsophila trichotoma Wender. Phytochemistry, 2013, 90, 114-127.

[23] Thakur, M.; Weng, A.; Pieper, A.; Mergel, K.; von Mallinckrodt, B.; Gilabert-Oriol, R.; Görick, C.; Wiesner, B.; Eichhorst, J.; Melzig, M.F.; Fuchs, H. Macromolecular interactions of triterpenoids and targeted toxins: Role of saponins charge. Int. J. Biol. Macromol., 2013, 61, 285-294.

[24] Ferreras, J.M.; Barbieri, L.; Girbés, T.; Battelli, M.G.; Rojo, M.A.; Arias, F.J.; Rocher, M.A.; Soriano, F.; Mendéz, E.; Stirpe, F. Distribution and properties of major ribosomeinactivating proteins (28S rRNA N0glycosidases) of the plant Saponaria officinalis L. (Caryophyllaceae). Biochim. Biophys. Acta, 1993, 1216, 31-42. 
[25] Puri, M.; Kaur, I.; Perugini, M.A.; Gupta, R.C. Ribosome-inactivating proteins: current status and biomedical applications. Drug Discov. Today, 2012, 17, 774-782.

[26] Lacaille-Dubois, M.A.; Wagner, H. Saponins. In: Atta-Urt-Rahman (Ed.), Studies in Natural Products Chemistry Series, Elsevier Science, 2012, 21, 633-687.

[27] Bonnet, A.; Chisholm, J.; Motherwell, W.D.S.; Jones, W. Hydrogen bonding preference of equatorial versus axial hydroxyl groups in pyran and cyclohexane rings in organic crystals. Cryst. Eng. Comm., 2005, 7, 71-75.

Table 1. Cytotoxic activities expressed by a cell index $(C I)$ per $1 \mu \mathrm{M}$ and indicator variables describing the chemical structure of studied saponins.

\begin{tabular}{ccccccc}
\hline saponin & $C I$ & $1 R$ & $2 \mathrm{COCH}_{3}$ & $3 \mathrm{SO}_{3} \mathrm{H}$ & $4 \mathrm{COCH}_{3}$ & $\mathrm{Xyl}$ \\
\hline $\mathbf{1}$ & 0.307 & 1 & 0 & 1 & 0 & 0 \\
$\mathbf{2}$ & 0.264 & 0 & 1 & 1 & 0 & 0 \\
$\mathbf{3}$ & 0.279 & 1 & 0 & 0 & 0 & 0 \\
$\mathbf{4}$ & 0.219 & 1 & 0 & 0 & 1 & 0 \\
$\mathbf{5}$ & 0.016 & 1 & 0 & 0 & 1 & 1 \\
$\mathbf{6}$ & 0.117 & 0 & 0 & 0 & 0 & 0 \\
$\mathbf{7}$ & 0.219 & 1 & 0 & 0 & 0 & 0 \\
$\mathbf{8}$ & 0.222 & 1 & 0 & 0 & 0 & 0 \\
$\mathbf{9}$ & 0.251 & 1 & 0 & 0 & 0 & 1 \\
\hline
\end{tabular}

\section{Figure legends:}

Figure 1. Structures of the studied saponins.

Figure 2. The score plot (a). The first $P C$ accounts for $41.3 \%$ of the variance in the dataset, the second PC - for $25.0 \%$. The loading plot (b). X and Y descriptors are given as grey and black circles, respectively.

Figure 3. The ideal saponin according to the QSAR model, derived in the present study. The synergistic cytotoxicity of saponins increases when $\mathrm{R}_{1}=\mathrm{H}, \mathrm{R}_{2}=\mathrm{H}, \mathrm{R}_{3}=\mathrm{H}, \mathrm{R}_{4}=\mathrm{COCH}_{3}$ and Sugar $=\mathrm{Xyl}$. 


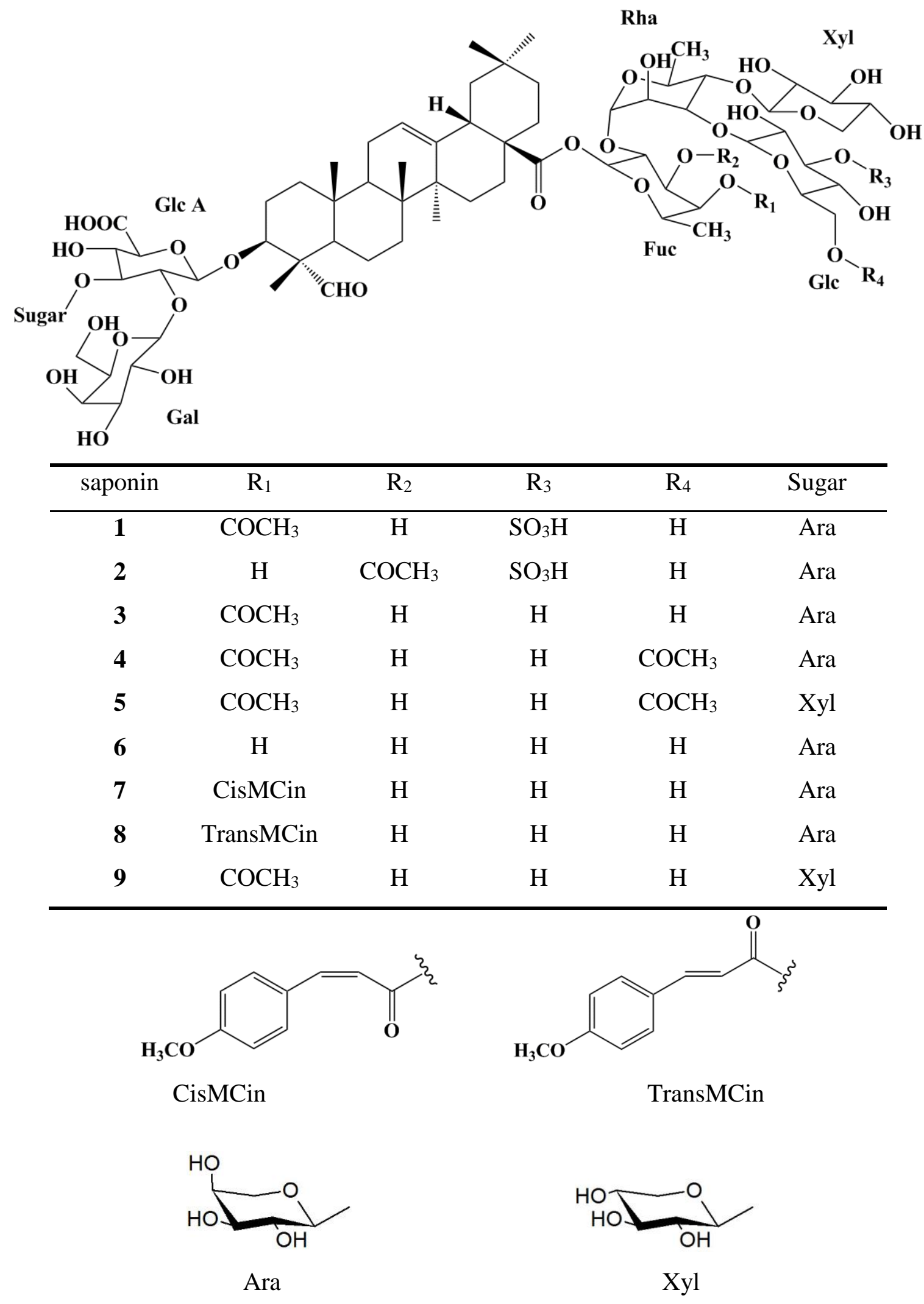

Figure 1. Structures of the studied saponins. 


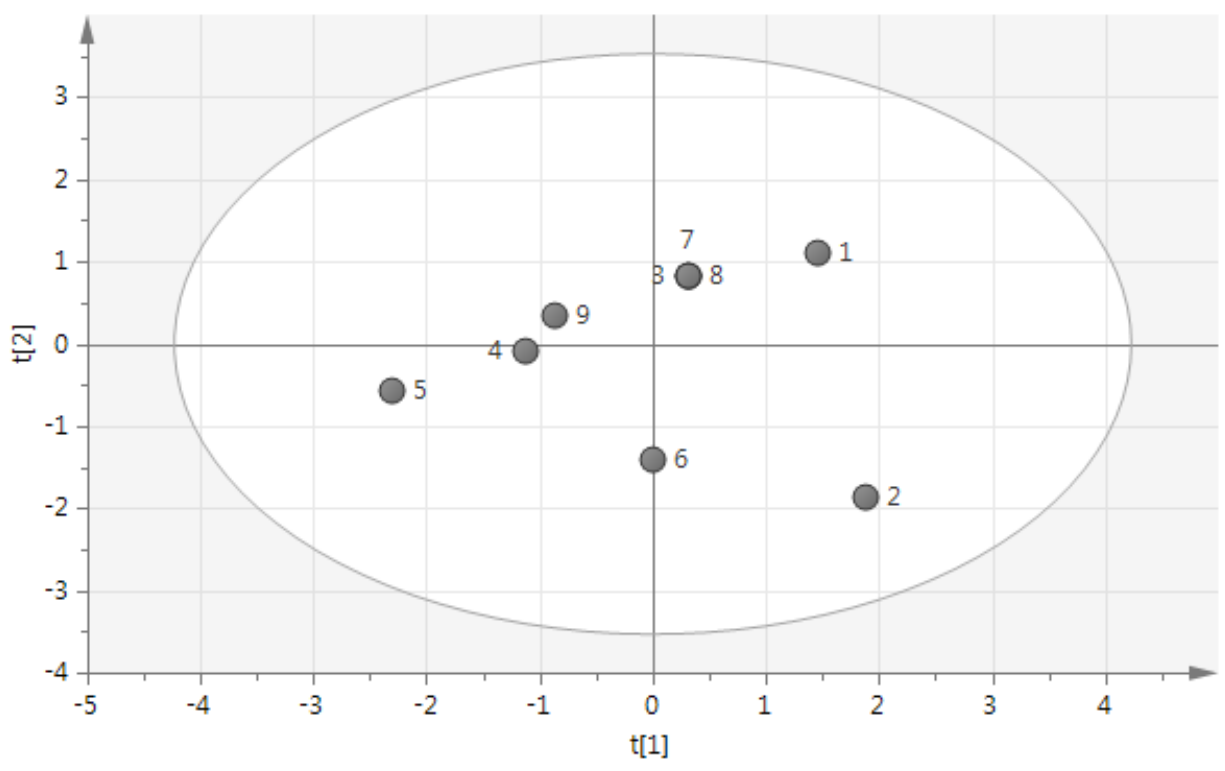

$\mathbf{a}$

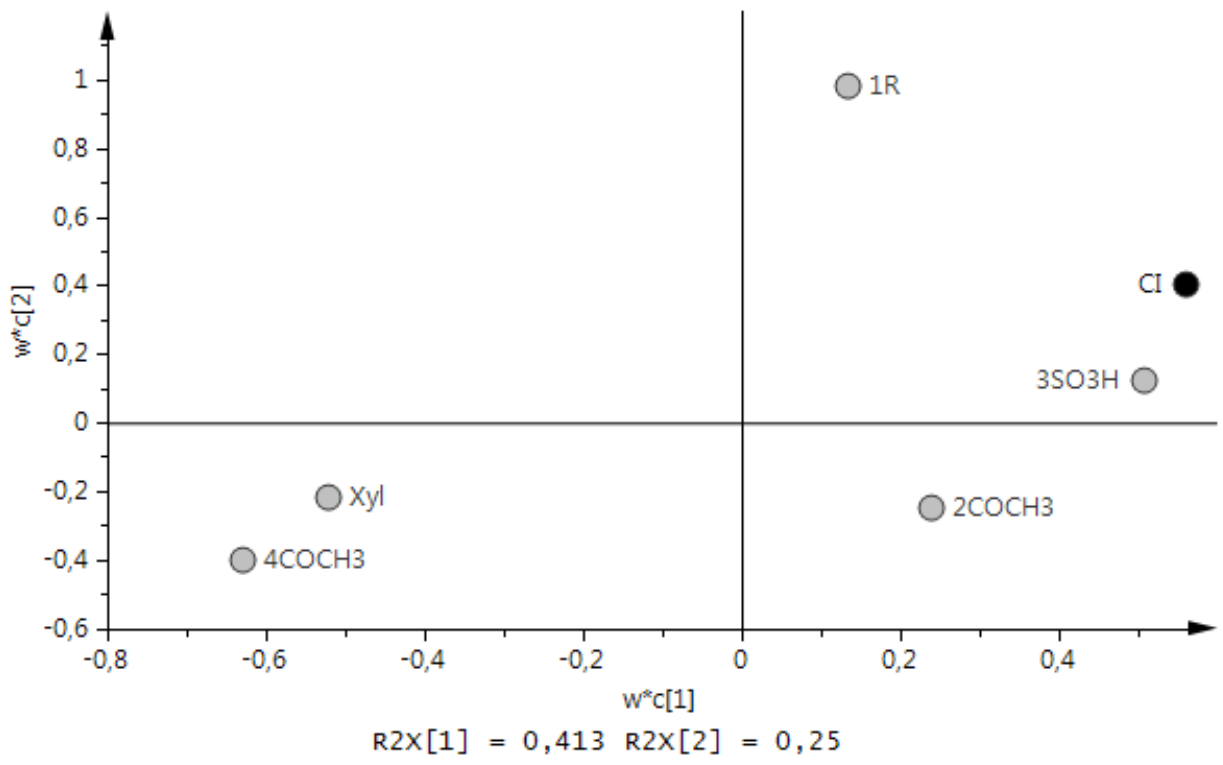

b

Figure 2. The score plot (a). The first $P C$ accounts for $41.3 \%$ of the variance in the dataset, the second PC - for $25.0 \%$. The loading plot (b). X and Y descriptors are given as grey and black circles, respectively. 


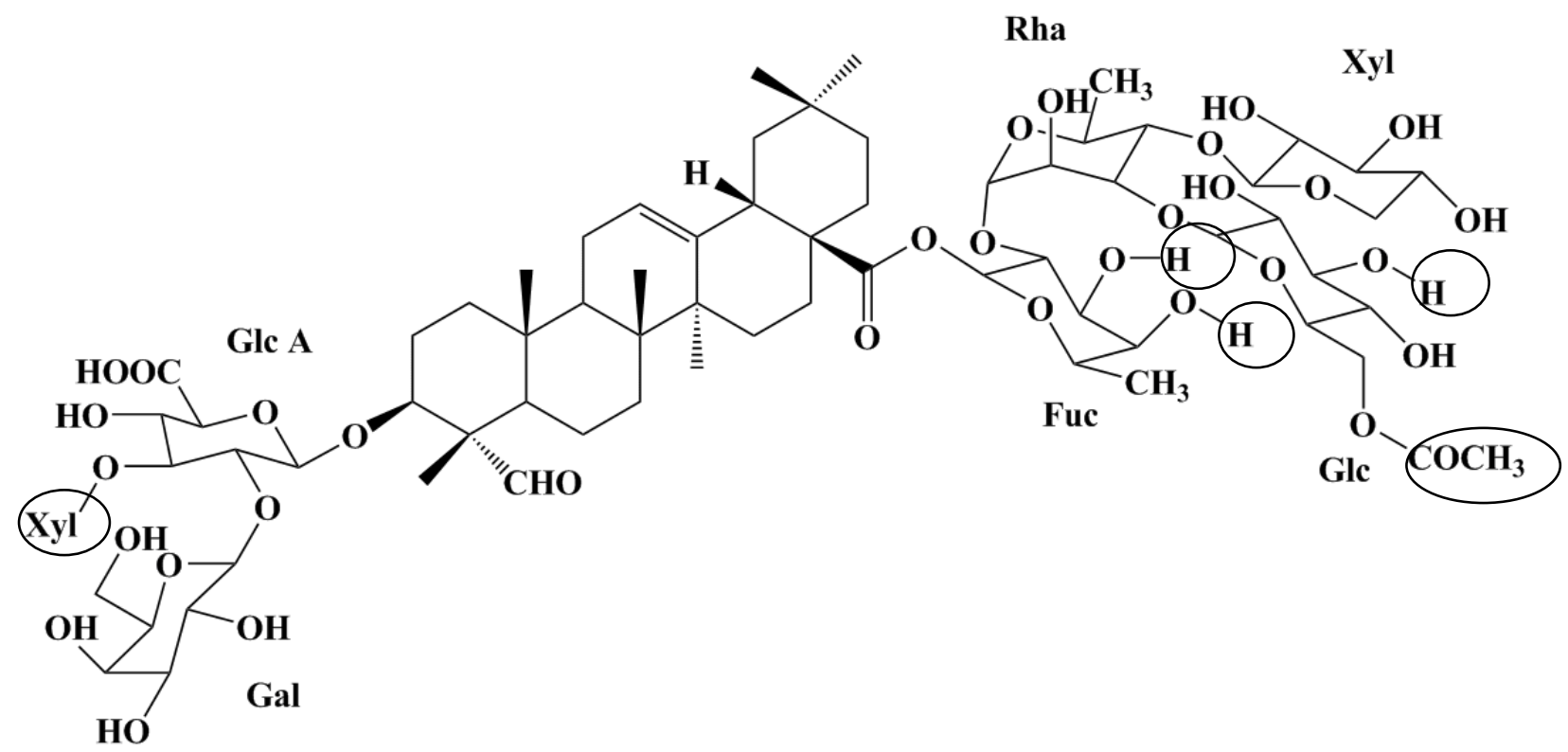

Figure 3. The ideal saponin according to the QSAR models, derived in the present study. The synergistic cytotoxicity of saponins increases when $\mathrm{R}_{1}=\mathrm{H}, \mathrm{R}_{2}=\mathrm{H}, \mathrm{R}_{3}=\mathrm{H}, \mathrm{R}_{4}=\mathrm{COCH}_{3}$ and Sugar $=$ Xyl 